\title{
Seasonalities in Eastern Foreign Exchange Markets: A Barrier to Euro Adoption?
}

\author{
Carlos Vieira and Isabel Vieira
}

Departamento de Economia, Universidade de Évora, Évora, Portugal

Centro de Estudos de Gestão, Instituto Superior Técnico, Universidade Técnica Lisboa, Lisbon, Portugal

(E-mail: cvieira@uevora.pt, impvv@uevora.pt)

\begin{abstract}
Plans for an early adoption of the euro by some new EU members hang on political will and a set of nominal criteria. The focus, however, should be on the available adjustment mechanisms supporting a permanently fixed exchange rate. Efficient financial markets could provide stabilisation (following a shock), substituting the weakened array of traditional policy instruments. In order to assess the availability of such alternative, this paper presents a particular empirical analysis of efficiency in the foreign exchange markets of three recently acceded countries. The results suggest that some caution is needed in the transition towards full monetary integration, as the level of financial efficiency already attained may be insufficient to ensure an adequate source of stabilisation in economies affected by specific disturbances.
\end{abstract}

Keywords: foreign exchange markets; calendar effects; financial integration; financial efficiency; euro adoption.

JEL classification: F31, F36, G14, G15.

Monetary integration precludes an independent use of some economic policy instruments and may hamper individual countries' ability to promote a rapid stabilisation process following a shock. This restriction is especially important when the degree of economic homogeneity among the members of an integrated area is low, and thus the probability of asymmetric shocks is high, or when no alternative adjustment mechanisms replace those eliminated in the process of integration. Perhaps taking these facts into consideration, no pressure has been exerted upon the newly integrated members of the European Union (EU) concerning the timing for their adoption of the common currency. 
They do not have the choice of opting out of full monetary integration, as others did before, and have to comply with the so-called Maastricht criteria before adopting the euro. Yet, it is in their hands to decide when to do so.

In spite of a lack of institutional pressure and of the known problems faced by countries such as Portugal, who has been struggling to control its economy within the dire straits of the Economic and Monetary Union (EMU), most new EU members seem to aspire to an early adoption of the common currency. Self-imposed deadlines have been made public and subsequently altered. Initially, they were displayed across a time span, ranging from 2006 to 2010 (Backé et al. 2004). Later, plans appear to have been postponed and news in the press have stated that the Hungarian government is currently planning to adopt the euro in 2013 (The Economist, 18 November 2006). However, bearing in mind the time needed to attain a sufficient level of real convergence, these countries' intention to join the euro sooner, rather than later, has raised a number of academic and political questions. ${ }^{1}$

A much discussed issue concerning monetary integration is the availability of alternative adjustment mechanisms, capable of replacing foreign exchange and individual monetary policy instruments in the short-term reaction to asymmetric shocks. In the EU case, the options appear to be quite limited. The common budget is too insignificant to provide automatic stabilisation, as is usually the case in federal organisations, and domestic fiscal autonomy is compromised by the stringent requirements of the Stability and Growth Pact. Furthermore, European labour markets are often labelled as relatively rigid, labour force is fairly immobile, and prices are sluggish. In such contexts, financial markets may be the only available source of stabilisation and adjustment following an asymmetric shock.

Economic theory suggests that financial markets may provide the smoothing of consumption in the aftermath of a negative disturbance, as long as that they are efficient and integrated..$^{2}$ Therefore, one way of adding value to the ongoing discussion concerning the proper timing for the new EU members' euro adoption is to empirically evaluate the level of financial efficiency and integration already attained. Empirical assessments of the degree of financial integration in the Central and Eastern European countries have been previously developed (Mansori 2003). However, to the best of our knowledge, no attempts have been made to assess these countries' financial efficiency. In this study, we focus our attention on the latter, approaching the issue of financial efficiency from the perspective of the information efficiency of foreign exchange markets.

Having in mind the rationale developed so far, such an analysis may be valid for two reasons. On the one hand, foreign exchange markets are usually the first segment of financial markets to be relieved from controls and regulations and, consequently, the first to become efficient and integrated. If evidence of segmentation is uncovered in foreign exchange markets, it is 
certainly present in other smaller, less liquid, and less cost-efficient segments of financial markets. In this case, the use of financial markets for purposes of economic stabilisation is compromised.

On the other hand, although the information efficiency of financial markets has been the object of countless analyses, the vast majority concentrates on stock markets, notwithstanding the importance of foreign exchange markets as the biggest segment of financial markets in terms of daily traded values. Besides, no conclusive explanations for most seasonal effects have been proposed so far, suggesting that further research is needed to improve our understanding of the phenomena.

The results of the analysis developed here are therefore of interest not only for their economic policy implications but also for their contribution to the financial efficiency literature. The methodology utilised in the empirical analysis is also relevant. Most similar analyses assume that the series of foreign exchange rates follow a normal distribution and use the minimisation of the sum of squares methodology. We use the alternative minimisation of the sum of absolute errors (MSAE) approach, which is considered to be more robust in estimations involving high-frequency financial data, with outliers and asymmetric distributions, as is the case here.

The remainder of the paper is organised as follows. First we discuss theoretical aspects of financial efficiency and survey the relevant empirical literature on information efficiency in foreign exchange markets. Then we demonstrate empirical assessments of weak-form information efficiency in the foreign exchange markets of three new EU members that have adopted the most flexible foreign exchange regime: the Czech Republic, Hungary, and Poland. Finally, we draw some conclusions and discuss implications of the empirical findings for the ongoing discussion on the timing for these countries' euro adoption.

\section{Efficiency of foreign exchange markets in theory and practice}

Financial markets' efficiency may be related to information processing, agents' rationality, or functional aspects. Information efficiency is by far the most popular concept amongst practitioners and academics. The hypothesis of efficient markets states that, if financial agents are efficient information processors, assets will be priced in accordance to their true or "just" value.

In a seminal paper, Fama (1970) defined three levels of information efficiency - weak, semistrong, and strong - differing in terms of the information sets relevant in the formation of financial agents' expectations. In the weakform efficiency, the information set contains past asset prices only. Current prices should therefore reflect all information contained on their past history, thus making it impossible to earn abnormal profits on the basis of chartist analyses. A time series of prices from a weak-form efficient market would follow a random walk. The semistrong and the strong efficiency forms rely on 
sets of, respectively, all publicly available and all information available, including confidential one. According to the former, only agents possessing inside information would be able to beat the market, whereas according to the latter this would be impossible even for those.

The information efficiency of financial markets has been subject to intense empirical investigation. Stock markets have largely been the most assessed, especially in their weak-form efficiency, by nature the less demanding in terms of data requirements. Among these tests, some concentrate on seasonal or calendar effects, such as the day-of-the-week effect, the month-ofthe-year effect, or the turn-of-the-month effect, and many display evidence of regularities that, although not always long-lived, identify periods of financial markets' inefficiency (for a good survey, see Keim and Ziemba [2000]).

Less attention has been directed towards foreign exchange markets. Such asymmetry of interest on the part of researchers may not be justified by the scarcity of available data, investors' indifference, or lack of theoretical ground. In fact, high-frequency foreign exchange quotes, for a large number of currencies, are readily available from multiple, credible sources. Foreign exchange variability is considered by international investors as a risk that must be taken into account, but also as a source of potential gains. In addition, the microeconomic approaches to foreign exchange rate determination consider the foreign exchange rate as one of many prices of assets traded in worldwide markets. There are, therefore, reasons to extend tests of efficiency to foreign exchange markets.

Empirical assessments of weak-form information efficiency of foreign exchange markets have tested the existence of calendar effects. Some analyses uncovered a number of apparent inefficiencies, in spite of their having been developed using data on currencies under floating regimes and, consequently, in the closest context to the theoretical notion of a perfect market.

One of the first published papers (McFarland et al. 1982) employed daily quotes collected from January 1975 to June 1979, to analyse eleven major and minor foreign exchange markets, concentrating on the statistical distribution properties of the data. McFarland et al. (1982) found different probability distributions for different trading intervals and obtained results suggestive of inefficiency. According to their conclusions, from the point of view of an American investor, returns on most of the assessed foreign currencies appear to be consistently higher on Mondays and Wednesdays and lower on Thursdays and Fridays.

So (1987) investigated whether the day-of-the-week effect uncovered by McFarland et al. (1982) was biased by the assumption of a symmetric distribution of foreign exchange returns. In accordance with the previous study, So (1987) found evidence of higher returns on Wednesdays and lower returns on Thursdays and Fridays, but obtained a contradictory result for Mondays. He concluded that the weekday effect weakens when the assumption of a 
symmetric distribution is relaxed and suggested that his finding of significant skewness within each day of the week is less "disturbing" for the notion of perfect markets than evidence of the same effect displayed by the mean of the returns.

Yamori and Mourdoukoutas (2003) and Yamori and Kurihara (2004) recently added to this literature by showing that for the most liquid currencies, calendar effects (and among these, especially the day-of-the-week effect) were visible in the 1980s but were practically absent in the 90s. These results are related to foreign exchange market deregulation and international integration, an intuition supported by analyses such as that of Aydoğan and Booth (2003), who found evidence of day-of-the-week and of week-of-the-month effects also in the first half of the 90s, for the less developed foreign exchange market of the Turkish lira.

The fact that calendar effects are more abundant in periods of market segmentation and tend to disappear, or become scarcer, following deregulation and abolishment of barriers to capital mobility, has also been reported for stock markets (Dubois and Louvet 1996). This suggests that maturity and efficiency come hand in hand with the development and sophistication of financial markets and, as suggested by economic theory, both characteristics appear to be enhanced by international integration. In what follows, we assess this tendency in a new set of countries, by investigating whether some calendar effects are still present in the foreign exchange markets of three recently acceded EU members: the Czech Republic, Hungary, and Poland. ${ }^{3}$ As they have started a process of transition towards market economies in the 1990s, it is interesting to evaluate if such an effort is already visible in tests of information efficiency in these countries' foreign exchange markets.

The choice of newly integrated transition countries is justified in this analysis for various reasons. Firstly, these countries were not previously studied in assessments of information efficiency of foreign exchange markets. Secondly, the option of financial stabilisation is particularly relevant for the newly integrated EU countries. In fact, although their singularity makes them more prone to asymmetric shocks, they have been experiencing exceptional financial inflows since the beginning of the transition process. Thirdly, the level of efficiency of foreign exchange markets is significant per se in transition economies, as it is linked to the international trade dynamics and is higher in countries labelled as "fast movers" as it is the case for the three studied here (Liargovas and Chionis 2001).

\section{Empirical analysis: day-of-the-week effect}

The empirical analysis in this section is performed with daily exchange rates of the Czech koruna, the Hungarian forint, and the Polish zloty against the U.S. dollar. The sample covers the period from January 1993 to May 2006, for 
a total of around 3400 observations, slightly varying with the number of national holidays. The data have been obtained from the countries' central bank databases. Using data from different sources, and different markets, implies that the comparability of the results may be affected by potentially different transaction or clearing systems in each country. However, tests performed with a shorter common database from an international financial institution do not qualitatively affect the results for the common period. ${ }^{4}$ The sample is also divided into two subsamples to assess the dynamics in market efficiency as the countries' financial markets develop and integrate into global markets. Given the relatively short period for which data are available, some caution is however necessary when interpreting the results for the subsamples.

Table 1 shows summary statistics of the exchange rate returns for the whole sample and the two subperiods. All three countries show positive mean returns until 1999 and negative mean returns afterwards, reflecting the recent steady appreciation of these currencies in the international markets, against the dollar and also against the euro, pushed in part by a flood of short-term capital inflows attracted by relatively higher interest rates. The three markets exhibit similar volatility values and patterns, with volatility increasing in the second half of the sample. As in other markets, volatility increases as amounts traded expand and more complex new financial instruments appear. All series are positively skewed and thick-tailed, compared with a normal distribution, a problem more significant in the first half of the sample and which will be dealt with later in the paper. The augmented Dickey-Fuller statistic tests for the null hypothesis of a unit root strongly rejected for all cases.

Table 1. Summary statistics of the exchange rate returns

\begin{tabular}{lllllll}
\hline $\begin{array}{l}\text { Country } \\
\text { and } \\
\text { period }\end{array}$ & $\begin{array}{l}\text { Nr. of } \\
\text { obser- } \\
\text { vations }\end{array}$ & Mean & $\begin{array}{l}\text { Standard } \\
\text { devia- } \\
\text { tion }\end{array}$ & $\begin{array}{l}\text { Skew- } \\
\text { ness }\end{array}$ & Kurtosis & $\begin{array}{l}\text { ADF } \\
\text { statistic }^{\text {a }}\end{array}$ \\
\hline $\begin{array}{l}\text { Czech Republic } \\
\text { 1993-06 }\end{array}$ & 3393 & -0.00810 & 0.66979 & 0.52643 & 11.076 & -57.891 \\
$1993-99$ & 1776 & 0.01231 & 0.63404 & 1.3716 & 20.805 & -43.115 \\
$2000-06$ & 1617 & -0.03052 & 0.70650 & -0.12868 & 3.8106 & -39.006 \\
$\begin{array}{l}\text { Hungary } \\
1993-06\end{array}$ & 3369 & 0.02622 & 0.67516 & 1.4678 & 22.438 & -31.335 \\
$1993-99$ & 1765 & 0.06209 & 0.53828 & 5.1798 & 82.897 & -20.891 \\
$2000-06$ & 1604 & -0.01325 & 0.79745 & 0.19968 & 4.9955 & -18.230 \\
$\begin{array}{c}\text { Poland } \\
1993-06\end{array}$ & 3384 & 0.01964 & 0.64205 & 0.61313 & 12.731 & -34.556 \\
$1993-99$ & 1763 & 0.05483 & 0.53376 & 1.5599 & 31.126 & -12.438 \\
$2000-06$ & 1621 & -0.01863 & 0.74037 & 0.27393 & 5.8064 & -39.969 \\
\hline
\end{tabular}

${ }^{a}$ Augmented Dickey-Fuller test statistic for the null hypothesis of a unit root 
Formal tests of the day-of-the-week effect in foreign exchange markets are usually performed in the empirical literature by regressing the daily mean returns on the five daily dummies, removing the intercept to avoid the wellknown dummy variable trap of perfect colinearity (Jaffe and Westerfield 1985, Cornett et al. 1995, Yamori and Mourdoukoutas 2003, Yamori and Kurihara 2004), and analysing the statistical significance of the day dummies, in order to identify the specific days of the week in which the effect occurs. However, besides the usual statistical problems of omitting the constant, the possible (in)significance of the dummy coefficients does not by itself reveal the (in)existence of a seasonal effect. The coefficient of a particular day may be statistically different from zero but not statistically different from that of the rest of the week, and consequently no day-of-the-week effect would exist. ${ }^{5}$ Therefore, in this paper, the following equation is estimated to investigate the existence of the-day-of-the-week effect:

$$
R_{t}=a_{0}+a_{1} \text { Dtue }_{t}+a_{2} \text { Dwed }_{t}+a_{3} \text { Dthu }_{t}+a_{4} \text { Dri }_{t}+\varepsilon_{t},
$$

where $R_{t}=100 * \log \left(S_{t} / S_{t-1}\right)$ are rates of return for holding a U.S. dollar for one trading day, with $S_{t}$ representing the national currency spot price of one U.S. dollar at time $t$, and each dummy variable $D_{t}$ takes the value one for the respective day of the week and zero otherwise. The Monday dummy has been dropped, so that all coefficients represent differences for Monday average returns, given by $a_{0}$. A positive return rate indicates a depreciation of the national currency against the U.S. dollar and therefore the $R_{t}$ are returns on the U.S. dollar to national investors.

The procedure usually adopted in empirical analyses involving stationary time series is to assume that the series follow a normal probability distribution and to obtain the estimators by minimising the sum of squared errors (MSSE). However, this may not be the most adequate procedure in this case, due to the uncertainties concerning the true distribution of high-frequency financial data, and especially of foreign exchange rates. Having the robustness of our analysis in view, we adopt a different methodology in the estimation of Eq. (1).

Apart from the commonly used MSSE criterion, alternatives include the MSAE and the minimisation of the maximum absolute error (MMAE). Works developed in the 1970s (for a survey, see Narula and Wellington [1977]) comparing the performance of the MSSE, the MSAE, and the MMAE regressions under various error distributions suggest that the second is more appropriate in the presence of long-tailed distributions, whereas the third is preferred when data present short tail. Such results indicate that in estimations involving daily exchange rates the aim should be to minimise the sum of absolute deviations. In fact, as Wang (2001) suggests, distributions of daily changes in exchange rates present long tails and are typically skewed to the left. Outliers are also usually present in this type of data samples, and in such 
conditions, it has been shown that the MSAE is preferable to the MSSE regression (Narula and Wellington 2007). In view of these facts, the MSAE estimation method is employed.

In the period under analysis, the three countries have undergone profound fundamental changes, with a rapid transition process towards a market economy and the integration in the EU. It is therefore expectable that the seasonal patterns of currency returns may have changed over time. To evaluate this hypothesis, as previously mentioned, the sample is divided approximately in half, with two subsamples for the periods from January 1993 to December 1999 and from January 2000 to May 2006. Table 2 shows the MSAE results for the complete sample and the two subsamples.

The results show that statistically significant coefficients occur only in Poland, where a day-of-the-week effect emerges on Tuesdays, Wednesdays, and Thursdays for the whole sample and for the second subperiod. This is somewhat against previous evidence for other countries showing that the effects tend to disappear as financial markets become more integrated and efficient. For Poland, however, this finding may be related to the chosen exchange rate regime, which has changed from a crawling-peg to a free floating system precisely in April 2000. No significant coefficients were found for the Czech Republic and Hungary, suggesting more efficient currency markets.

In order to improve the robustness of the analysis developed so far, an alternative nonparametric approach is also adopted. Here, the assessment of a day-of-the-week effect is based on the statistical analysis of the daily average mean returns and the standard deviations. As shown in Table 3, the highest daily returns are found in the middle of the week, while the lowest returns concentrate mostly around the weekend, on Mondays in Hungary and Poland and on Fridays in the Czech Republic. In fact, Hungary and Poland share a

Table 2. Day-of-the-week effect, MSAE regressions ${ }^{\text {a }}$

\begin{tabular}{|c|c|c|c|c|c|c|c|c|c|}
\hline \multirow[t]{2}{*}{ Weekday } & \multicolumn{3}{|c|}{ Czech Republic } & \multicolumn{3}{|l|}{ Hungary } & \multicolumn{3}{|l|}{ Poland } \\
\hline & $\begin{array}{l}1993- \\
2006\end{array}$ & $\begin{array}{l}1993- \\
1999\end{array}$ & $\begin{array}{l}2000- \\
2006\end{array}$ & $\begin{array}{l}1993- \\
2006\end{array}$ & $\begin{array}{l}1993- \\
1999\end{array}$ & $\begin{array}{l}2000- \\
2006\end{array}$ & $\begin{array}{l}1993- \\
2006\end{array}$ & $\begin{array}{l}1993- \\
1999\end{array}$ & $\begin{array}{l}2000- \\
2006\end{array}$ \\
\hline Tuesday & $\begin{array}{c}0.00533 \\
(0.03801)\end{array}$ & $\begin{array}{c}0.02571 \\
(0.04597)\end{array}$ & $\begin{array}{c}0.01813 \\
(0.07071)\end{array}$ & $\begin{array}{c}-0.02512 \\
(0.03169)\end{array}$ & $\begin{array}{c}-0.05788 \\
(0.03703)\end{array}$ & $\begin{array}{c}0.06935 \\
(0.07948)\end{array}$ & $\begin{array}{c}0.05160^{*} \\
(0.03013)\end{array}$ & $\begin{array}{c}0.02723 \\
(0.03134)\end{array}$ & $\begin{array}{c}0.10802^{*} \\
(0.06012)\end{array}$ \\
\hline $\begin{array}{l}\text { Wednes- } \\
\text { day }\end{array}$ & $\begin{array}{c}0.02681 \\
(0.03806)\end{array}$ & $\begin{array}{c}-0.00966 \\
(0.04603)\end{array}$ & $\begin{array}{c}0.07286 \\
(0.07077)\end{array}$ & $\begin{array}{c}-0.01561 \\
(0.03174)\end{array}$ & $\begin{array}{c}-0.03779 \\
(0.03708)\end{array}$ & $\begin{array}{c}-0.00012 \\
(0.07965)\end{array}$ & $\begin{array}{c}0.05104^{*} \\
(0.03012)\end{array}$ & $\begin{array}{c}0.00590 \\
(0.03134)\end{array}$ & $\begin{array}{c}0.16109^{* * * *} \\
(0.06008)\end{array}$ \\
\hline Thursday & $\begin{array}{c}0.02863 \\
(0.03807)\end{array}$ & $\begin{array}{c}0.02921 \\
(0.04606)\end{array}$ & $\begin{array}{c}0.03550 \\
(0.07077)\end{array}$ & $\begin{array}{c}0.01850 \\
(0.03172)\end{array}$ & $\begin{array}{c}0.01375 \\
(0.03714)\end{array}$ & $\begin{array}{c}0.02422 \\
(0.07948)\end{array}$ & $\begin{array}{c}0.05303^{*} \\
(0.03029)\end{array}$ & $\begin{array}{c}0.03480 \\
(0.03154)\end{array}$ & $\begin{array}{c}0.11497^{*} \\
(0.06040)\end{array}$ \\
\hline Friday & $\begin{array}{c}0.01849 \\
(0.03801)\end{array}$ & $\begin{array}{c}0.01450 \\
(0.04603)\end{array}$ & $\begin{array}{c}0.02385 \\
(0.07061)\end{array}$ & $\begin{array}{c}-0.02751 \\
(0.03183)\end{array}$ & $\begin{array}{c}-0.05376 \\
(0.03729)\end{array}$ & $\begin{array}{c}0.03467 \\
(0.07959)\end{array}$ & $\begin{array}{c}0.03920 \\
(0.03016)\end{array}$ & $\begin{array}{c}0.02400 \\
(0.03145)\end{array}$ & $\begin{array}{c}0.09339 \\
(0.06003)\end{array}$ \\
\hline
\end{tabular}

${ }^{a}$ In parentheses, values are standard errors. Single and triple asterisks denote significance at the 1 and 10 per cent levels, respectively 
Table 3. Daily mean returns and standard deviations ${ }^{\mathrm{a}}$

\begin{tabular}{cccccc}
\hline $\begin{array}{l}\text { Country and } \\
\text { period }\end{array}$ & Monday & Tuesday & Wednesday & Thursday & Friday \\
\hline Czech Republic & & & & \\
1993-06 & -0.01504 & 0.00218 & 0.01027 & -0.01448 & -0.02360 \\
& $(0.69203)$ & $(0.69193)$ & $\left(0.74985^{* * *}\right)$ & $\left(0.60703^{* * *}\right)$ & $\left(0.59787^{* * *}\right)$ \\
$1993-99$ & 0.00114 & 0.04401 & $0.01376^{* * *}$ & $0.00092^{* * *}$ & $\left.0.001229^{* * *}\right)$ \\
& $(0.60863)$ & $\left(0.68969^{* *}\right)$ & $\left(0.76539^{* *}\right)$ & $\left(0.53165^{* * *}\right)$ & $\left(0.54489^{* *}\right)$ \\
2000-06 & -0.03275 & -0.04402 & 0.00643 & -0.03140 & -0.05069 \\
& $(0.773689)$ & $(0.69252)$ & $(0.73351)$ & $(0.68074)$ & $\left(0.65058^{* *}\right)$ \\
Hungary & & & & \\
$1993-06$ & 0.00394 & 0.02173 & 0.01496 & 0.05390 & 0.03550 \\
& $\left(0.78769^{* * *}\right)$ & $\left(0.58925^{* * *}\right)$ & $\left(0.62296^{* * *}\right)$ & $\left(0.63484^{* *}\right)$ & $\left(0.72923^{* * *}\right)$ \\
$1993-99$ & 0.07664 & 0.03066 & 0.05536 & 0.08074 & 0.06813 \\
& $\left(0.71164^{* * *}\right)$ & $\left(0.40052^{* * *}\right)$ & $\left(0.39991^{* * *}\right)$ & $\left(0.43746^{* * *}\right)$ & $\left(0.66799^{* * *}\right)$ \\
2000-06 & -0.07733 & 0.01187 & -0.02982 & 0.02458 & 0.00024 \\
& $\left(0.85875^{* *}\right)$ & $\left(0.74461^{*}\right)$ & $(0.79901)$ & $(0.79611)$ & $(0.78961)$ \\
Poland & & & & \\
$1993-06$ & $-0.03225^{* *}$ & 0.03339 & 0.00165 & $0.05871^{* *}$ & 0.03586 \\
& $\left(0.69025^{* * *}\right)$ & $\left(0.60147^{* * *}\right)$ & $(0.63152)$ & $(0.63077)$ & $(0.65250)$ \\
$1993-99$ & 0.03226 & 0.05809 & 0.02720 & 0.08771 & 0.06879 \\
& $\left(0.58967^{* * * *}\right)$ & $(0.53197)$ & $\left(0.46976^{* * *}\right)$ & $\left(0.44319^{* * *}\right)$ & $\left(0.61613^{* * *}\right)$ \\
2000-06 & $-0.10100^{* *}$ & 0.00619 & -0.02641 & 0.02699 & 0.00032 \\
& $(0.77843)$ & $\left(0.66951^{* * *}\right)$ & $(0.77082)$ & $\left(0.78587^{*}\right)$ & $\left(0.68878^{* * *}\right)$ \\
\hline
\end{tabular}

${ }^{a}$ In parentheses, values are standard deviations. Single, double, and triple asterisks refer to the rejection of the null hypothesis of equal means or variances at 1, 5, and 10 percent levels, respectively. The means test is a two-sample $t$ test with unequal variances

very similar pattern, possibly reflecting some common phenomena in both countries, with the higher returns found always on Thursdays, both for the whole and subperiods, and the lowest daily returns arising on Mondays. The first day of the week also shows, on average, a higher volatility of exchange rate returns.

A simple approach to assess the existence of a day-of-the-week effect involves performing $t$ tests and nonparametric Mann-Whitney $\mathrm{U}$ tests on the hypothesis that the mean return on each weekday is equal to the mean return on the rest of the week, assuming unequal variances. Table 3 shows these results, with the usual asterisks indicating the cases for which the null hypothesis of equal means has been rejected. Again, only Poland seems to demonstrate a significant day-of-the-week effect. At the usual five per cent significance level, the only significantly different mean returns occur on Mondays in the complete sample and in the second subperiod.

However, this mean returns analysis should be complemented with a volatility analysis to examine whether the expected relationship between returns and risk breaks up. Accordingly, Table 3 also shows the results of tests on the equality of variances between each weekday and the rest of the week. 
The results demonstrate a pattern of quite diverse risk behaviour on the different days of the week, apparently not connected with the pattern of mean returns, which may be interpreted as evidence of inefficiencies in the countries' financial markets. In fact, the identification of more profitable trading days may only be considered as a financial anomaly if they are not accompanied by higher volatility, an assumption usually disregarded in this literature. This is clearly the case here as, in most cases, the days with higher mean returns are not those with the highest volatilities. Nevertheless, such pattern occurs especially in the first subperiod, suggesting that these forex markets, although demonstrating higher volatility in more recent years, are becoming less inefficient in this respect.

\section{Concluding remarks}

This study assesses the weak-form information efficiency in three recently integrated EU countries, with the objective of evaluating minimum conditions theoretically required to opt for economic stabilisation via financial markets. This option is especially relevant for the Czech Republic, Hungary, and Poland, in view of their intention of adopting the euro in the near future, before attaining the levels of real convergence that would diminish the probability of their being hit by asymmetric shocks and, therefore, augmenting the need for alternative adjustment mechanisms.

It is not possible to assess the ability of financial markets to smooth consumption following a shock by merely analysing the level of efficiency of foreign exchange markets. However, economic theory suggests that financial markets may be used for stabilisation purposes only if they are efficient and integrated. Since foreign exchange markets are the largest, the more dynamic and the more efficient segment of financial markets, they are the first to demonstrate the characteristics of integrated markets when barriers to the free flow of capital are removed, and they are the quickest to show some evidence of efficiency following integration. To find out, as we do here, that inefficiencies still persist, and in some cases have recently increased, in the foreign exchange markets of the more actively traded Eastern European currencies, suggests that the financial markets of some of these countries may be unprepared to efficiently perform the role of stabilisers. In such conditions, it is questionable whether these countries should adopt the single currency in the short run, as the decision implies giving up policy tools that could be necessary to react to idiosyncratic shocks.

In order to produce a robust empirical analysis and to overcome the problems that may arise in traditional least-squares estimations involving high-frequency foreign exchange rates, alternative parametric and nonparametric techniques were adopted. However, in the analysis of daily mean 
returns, whatever the methodology, only the Polish zloty appears to present abnormal profit opportunities. When the study is further developed by analysing the relationship between return and risk on each day, the evidence demonstrates anomalies in all the three markets, although more evident in the first half of the sample. This is in accordance with previous results for other currency markets, suggesting that anomalies tend to lose their strength in recent years, following improvements in liberalisation and integration. Nevertheless, the overall analysis suggests that some form of currency market inefficiency still exists in the three countries, either in means or in variances.

In general terms, Poland shows the stronger signs of inefficiency. If it is reasonable to expect that countries with less efficient financial markets would prefer to postpone the adoption of the common currency until a higher level of real convergence has been attained, the obtained results are clearly at odds with the self-declared intentions of these countries. According to Backé et al. (2004), the Czech Republic was planning to adopt the euro around 2009/10, Hungary in January 2008, and Poland around 2008 or 2009. The differences in timings are not substantial but, in the context of the present study, the decisions could be a bit premature, especially for Poland.

A more cautious attitude has recently been emerging. The self-proposed deadlines have been adjusted and public statements sound now less enthusiastic. In fact, the governor of the Czech central bank has publicly defended the advantages of an independent monetary policy, the Polish government announced a possible referendum for 2010 (although opting-out of the euro is not an alternative for the new EU members) and Hungarians postponed the euro adoption for 2013. The prudence reflected in these more cautious announcements is consistent with the policy implications of our analysis and with the apparent lack of minimum conditions for financial stabilisation in countries intending to give up monetary autonomy in the near future. In the current context, either these countries postpone the adoption of the euro until a higher level of real convergence has been achieved, or they will have to be prepared to trade the benefits of an early EMU membership for the social and political costs attached to longer and harder recoveries, whenever domestic economic conditions are not in line with those of the rest of the euro zone.

\section{Notes}

1 Assuming a 1.5\% annual growth for the EU15 gross domestic product and growth rates for the new EU members that double those registered in 2002, Bolle (2004) shows that the Czech Republic, Hungary, and Poland would achieve 80\% convergence to EU15 gross domestic product in 2014, 2011 and 2048, respectively.

2 The role of international capital flows in the process of economic adjustment and stabilisation has been highlighted by many authors (e.g., Allsopp and Vines 1998). 
3 Dean (2004) classifies the ten new EU members in terms of their foreign exchange regimes as large floaters (the Czech Republic, Hungary and Poland) and small peggers.

4 For the sake of brevity, these tests are not shown, but are available upon request.

5 Although it does not identify the specific day when the effect occurs, that specification allows testing for its existence, through a Wald test of the null hypothesis that all coefficients are equal. The results, not shown, do not contradict the conclusions stated above.

\section{References}

Allsopp C, Vines D (1998) The assessment: macroeconomic policy after EMU. Oxford Review of Economic Policy 14(3): 1-23

Aydoğan K, Booth G (2003) Calendar anomalies in the Turkish foreign exchange markets. Applied Financial Economics 13: 353-360

Backé P, Thimann C, Arratibel O, Calvo-Gonzalez O, Mehl A, Nerlich C (2004) The acceding countries' strategies towards ERM II and the adoption of the euro: an analytical review. ECB Occasional Paper 10. European Central Bank, Frankfurt am Main

Bolle M (ed) (2004) Eurozone enlargement - exploring uncharted waters. BWV Berliner Wissenschafts-Verlag, Berlin

Dean J (2004) Adopting the euro: tradeoffs and challenges facing the new EU-ten. Journal of Policy Modelling 26: 759-767

Dubois M, Louvet P (1996) The day-of-the-week effect: the international evidence. Journal of Banking and Finance 20: 1463-1484

Fama E (1970) Efficient capital markets: a review of theory and empirical work. Journal of Finance 25: $383-417$

Jaffe J, Westerfield R (1985) The week-end effect in common stock returns: the international evidence. Journal of Finance 40: 433-454

Keim D, Ziemba W (2000) Security market imperfections: an overview. In: Keim D, William Z (eds) Security market imperfections in world wide equity markets. Cambridge University Press, Cambridge

Liargovas P, Chionis D (2001) Economic integration between the European Union and the transition economies of Central European Initiative countries. Post-Communist Economies 13: $57-70$

Mansori K (2003) Following in their footsteps: comparing interest parity conditions in Central European countries to the euro countries. CESifo Working Paper1020. Münchener Gesellschaft zur Förderung der Wirtschaftswissenschaften - CESifo GmbH, Munich

McFarland J, Pettit R, Sung S (1982) The distribution of foreign exchange price changes: trading day effects and risk measurement. Journal of Finance 37: 693-715

Narula S, Wellington J (1977) Prediction, linear regression and the minimum sum of relative errors. Technometrics 2: 185-190

Narula S, Wellington J (2007) Multiple criteria linear regression. European Journal of Operational Research 181: 767-772

So J (1987) The distribution of foreign exchange price changes: trading day effects and risk measurement: a comment. Journal of Finance 42: 181-188

Wang J (2001) Generating daily changes in market variables using a multivariate mixture of normal distributions. In: Peters B, Smith J, Medeiros D, Rohrer M (eds) Proceedings of the 2001 Winter Simulation Conference, vol 1. IEEE Computer Society, Washington, DC, pp 283-289

Yamori N, Kurihara Y (2004) The day-of-the-week effect in foreign exchange markets: multicurrency evidence. Research in International Business and Finance 18: 51-57

Yamori N, Mourdoukoutas P (2003) Does the day-of-the-week effect in foreign currency markets disappear? Evidence from the yen/dollar market. International Finance Review 4: 443-459 